\title{
BMJ Open Development in the number of clinical trial applications in Western Europe from 2007 to 2015: retrospective study of data from national competent authorities
}

\author{
Tilde Dombernowsky, ${ }^{1}$ Merete Hædersdal, ${ }^{1}$ Ulrik Lassen, ${ }^{2}$ \\ Simon Francis Thomsen ${ }^{1,3}$
}

To cite: Dombernowsky T, Hædersdal M, Lassen U, et al. Development in the number of clinical trial applications in Western Europe from 2007 to 2015: retrospective study of data from national competent authorities. BMJ Open 2017;7:e015579. doi:10.1136/ bmjopen-2016-015579

- Prepublication history and additional material for this paper are available online. To view these files please visit the journal online (http://dx.doi. org/10.1136/bmjopen-2016015579).

Received 16 December 2016 Revised 5 May 2017 Accepted 31 May 2017

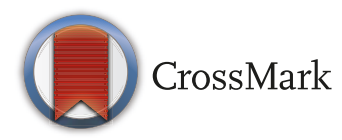

${ }^{1}$ Department of Dermatology, Copenhagen University Hospital Bispebjerg, Copenhagen, Denmark

${ }^{2}$ Department of Oncology, Copenhagen University Hospital Rigshospitalet, Copenhagen, Denmark

${ }^{3}$ Department of Biomedical Sciences, University of Copenhagen, Copenhagen, Denmark

Correspondence to Dr Tilde Dombernowsky; dombernowsky@gmail.com

\section{ABSTRACT}

Objective To investigate the development in the number of applications for authorisation of clinical trials of medicines (CTAs) submitted annually to national competent authorities in 10 Western European member states of the European Union from 2007 to 2015. Design Registry study.

Setting Data from national competent authorities. Participants Germany, Italy, Spain, France, the UK, Belgium, the Netherlands, Austria, Denmark and Sweden Inclusion criteria were Western European member states of the European Union, receiving more than 200 CTAs per year.

Outcome measures Summarised number of CTAs and distribution of CTAs by type of sponsor (commercial or non-commercial) and trial phase (I-IV). Average annual growth rates (AAGRs) based on linear regressions. Data were evaluated 2007-2011 and 2012-2015 to compare findings with the European Commission's statement of a 25\% decrease in CTAs in the EU from 2007 to 2011.

Results From 2007 to 2011, the summarised number of CTAs decreased significantly (AAGR $-3.9 \%(p=0.02)$ ), primarily due to a decrease in commercially sponsored CTAs. From 2012 to 2015, the change was insignificant (AAGR 2.6\% $(p=0.27))$, however with a $10 \%$ increase from 2014 to 2015 after stagnation from 2012 to 2014. Overall, the number of CTAs and distribution by type of sponsor varied considerably between countries. No distinct trends were observed when evaluating CTAs by type of trial phase.

Conclusions This study found a significant decrease in the number of CTAs in Western Europe from 2007 to 2011 (AAGR $-3.9 \%$ ). This development is possibly attributable to several factors such as the European Clinical Trials Directive, national and local political decisions, and a potential global shift in clinical trial activity. From 2014 to 2015 , the number of CTAs increased markedly $(10 \%)$. However, it is yet too soon to determine if this constitutes a transient fluctuation or a new trend.

\section{INTRODUCTION}

Approximately 4000 clinical trials of medicines are authorised annually in the European
Strengths and limitations of this study

- This registry study is one of only few studies presenting detailed data on clinical trial activity in Western Europe.

- Data on the annual number of applications for clinical trials of medicines in 10 countries were included; as these countries are responsible for the vast majority of clinical trials of medicines conducted in Western Europe, the data represent Western Europe as a whole.

- The number of clinical trial applications does not precisely reflect the number of clinical trials of medicines conducted as some applications are rejected, some trials are never conducted, and in multinational trials, multiple applications represent one clinical trial.

- The summarised number of clinical trial applications in 2015 is only an approximation as data from 2015 were not available from one out of the 10 countries included.

Union (EU). ${ }^{1}$ The majority of these trials are conducted in Western European countries, but the number of clinical trials of medicines in this region seems to decrease. According to the European Commission, the number of applications for authorisation of clinical trials of medicines (CTAs) decreased by $25 \%$ from 2007 to 2011 in the EU as a whole. ${ }^{2}$ A decline in clinical trial activity may have negative implications for patients, healthcare professionals and society, as clinical trials are central in discovering new medical treatments and improvement of medical care. Therefore, several initiatives have emerged in the last five to eightyears to improve conditions for the conduct of clinical trials in Europe. Among these, the Voluntary Harmonisation Procedure was implemented in 2009 to improve regulatory time to approval and make the 
application procedure in multinational trials easier for the sponsor. ${ }^{3}$ Furthermore, standard contracts have been developed, and evolvement of national disease specific research networks is a priority in some countries.

Few studies have examined the development in CTAs in Western Europe. One of these studies found that from 2001 to 2009, the number of CTAs decreased in four out of the six Western European countries that are responsible for the highest number of clinical trials of medicines. ${ }^{4}$ Another study found that the number of CTAs decreased in three out of four Scandinavian countries in the period 2007-2011..$^{5}$ To our knowledge, no previous study has examined the development in the number of CTAs in Western Europe as a whole during the period 2007-2011 or since 2011.

Accordingly, the objective of this study is to investigate the development in the number of CTAs submitted annually to national competent authorities in 10 Western European member states of the EU from 2007 to 2015. Specifically, the aims are to (1) evaluate the development in the summarised number of CTAs, (2) evaluate the development in the number of CTAs by type of sponsor and trial phase also taking into account the development in the individual countries and (3) determine the percentage change in the summarised number of CTAs from 2007 to 2011 to compare our findings with the European Commission's statement of a $25 \%$ decrease in the number of CTAs in the EU during this period.

\section{METHODS}

We evaluated the number of CTAs submitted annually to the national competent authorities in the following Western European EU member states in the period 2007-2015: Germany, Italy, Spain, France, the UK, Belgium, the Netherlands, Austria, Denmark and Sweden. The inclusion criteria were Western European EU member states, receiving more than 200 CTAs per year. By including these countries, data represent the development in Western Europe as a whole as these countries together account for approximately $90 \%$ of all CTAs in Western Europe. The distribution of CTAs by type of sponsor (commercial or non-commercial) and trial phase (I-IV) was determined. However, data on type of trial phase were not available from France, and phase II and III clinical trials are registered together by the UK and could therefore not be separated. The type of sponsor and trial phase were defined according to the European Commission's application form for the request for authorisation of a clinical trial, which is completed by the sponsor when applying for authorisation of a clinical trial. ${ }^{6-8}$ Data sources appear in online supplementary appendix 1 . Data were primarily extracted from publicly available annual reports and statistics published on the websites of the national competent authorities. The remaining data were extracted from reports published by consulting firms and supplied by the national competent authorities by email.
Data were evaluated with regard to two periods: 2007-2011 and 2012-2015. The period 2007-2011 was specifically selected to compare our findings with the European Commission's statement of a 25\% decrease in the number of CTAs in the EU during this period. The development in CTAs by type of sponsor and trial phase in each country was described using average annual growth rates (AAGRs), inspired by Hartmann (table 1$).{ }^{4}$ The total number of CTAs for all countries was addressed as the summarised number of CTAs to specify that the number refers to a summation of CTAs of which some refer to the same clinical trial. In contrast to the other countries included, the number of CTAs in Italy in 2015 is not yet available from the Italian national competent authorities. Therefore, we estimated this number to complete the data of the summarised number of CTAs for all countries in 2015 (online supplementary appendix 2).

\section{Statistics}

Univariate linear regression analysis was used to evaluate the development in CTAs over time. AAGRs for the summarised number of CTAs and number of CTAs in each country were calculated based on the univariate linear regressions $(\mathrm{AAGR}=100 \times(\mathrm{C}[\mathrm{n}] /(\mathrm{C}[\mathrm{n}-1]$ $-1)$ ), where $C[n]$ is the number of CTAs in year $n)$. The $R^{2}$ values and $p$ values of the trendlines were determined to evaluate potentially significant changes in the number of CTAs over time. $p$ Values $\leq 0.05$ were considered statistically significant. The statistical analysis was also applied to the subsets of data regarding type of sponsor and trial phase. Data were analysed using Statistical Analysis System (SAS) V.9.4.

The percentage change in the summarised number of CTAs from 2007 to 2011 was determined using the observed values (not the estimated values on the trend line) to make comparison with the European Commission's statement of a $25 \%$ decrease in the number of CTAs in the EU possible.

\section{RESULTS}

The summarised number of CTAs did not change significantly during the observation period as a whole $(2007-2015)$ (AAGR -1.4\% $(\mathrm{p}=0.08))$ (table 1). As illustrated in figure 1, between 6101 and 7084 CTAs were submitted annually in the period 2007-2015. On average, $74 \%$ of the CTAs were commercially sponsored and $26 \%$ were non-commercially sponsored with only little variability (SD 0.9\%). The development in the number of CTAs in the individual countries appears in figures $2 \mathrm{a}, \mathrm{b}$ and c. Overall, the number of CTAs and the distribution of CTAs by type of sponsor varied considerably between countries. Phase III clinical trials were the most common type of trial applied for in each country, constituting between $34 \%$ and $45 \%$ of all submitted CTAs (figure 3 ).

\section{The period 2007-2011}

The summarised number of CTAs decreased significantly from 2007 to 2011 with an AAGR of $-3.9 \% \quad(p=0.02)$ 
Table 1 Average annual growth rates (AAGRs) of the number of clinical trial applications (CTAs) by type of sponsor and trial phase in 10 Western European countries ${ }^{+}$

\begin{tabular}{|c|c|c|c|c|c|c|c|}
\hline \multirow[b]{2}{*}{ Country } & \multirow[b]{2}{*}{ Total CTAst } & \multicolumn{2}{|c|}{ CTAs by type of sponsor } & \multicolumn{4}{|c|}{ CTAs by type of trial phase } \\
\hline & & $\begin{array}{l}\text { Commercially } \\
\text { sponsored CTAs }\end{array}$ & $\begin{array}{l}\text { Non-commercially } \\
\text { sponsored CTAs }\end{array}$ & $\begin{array}{l}\text { Phase I } \\
\text { CTAs }\end{array}$ & $\begin{array}{l}\text { Phase II } \\
\text { CTAs }\end{array}$ & $\begin{array}{l}\text { Phase III } \\
\text { CTAs }\end{array}$ & $\begin{array}{l}\text { Phase IV } \\
\text { CTAs }\end{array}$ \\
\hline \multicolumn{8}{|c|}{ AAGRs in the period $2007-2015(\%)$} \\
\hline All countries & -1.4 & -1.5 & -1.1 & $-2.8^{\star}$ & $-2.2^{*}$ & -0.9 & $-4.3^{\star}$ \\
\hline Germany & $-3.7^{\star}$ & $-3.2^{*}$ & $-6.0^{* *}$ & $-5.9^{\star}$ & $-3.3^{\star}$ & $-1.8^{*}$ & $-5.7^{\star}$ \\
\hline Italył & $-3.9^{*}$ & -1.6 & $-8.5^{\star}$ & $9.6^{\star}$ & $-6.1^{*}$ & $-5.0^{*}$ & $-9.5^{\star}$ \\
\hline Spain & $2.3^{*}$ & 1.9 & 3.5 & $5.9^{* *}$ & 1.2 & $3.5^{\star}$ & $-3.2^{*}$ \\
\hline France & 0.9 & 0.9 & 0.9 & - & - & - & - \\
\hline The UK§ & -1.5 & -1.2 & -2.5 & $-5.1^{\star \star}$ & \multicolumn{2}{|c|}{2.5} & $-8.6^{\star}$ \\
\hline Belgium & 0.4 & -0.9 & $6.6^{*}$ & -0.9 & -0.8 & 1.5 & 2.6 \\
\hline The Netherlands & -1.1 & -1.2 & -1.1 & -0.6 & 1.8 & -1.4 & -2.9 \\
\hline Austria & $-2.8^{\star}$ & -3.7 & -0.5 & -1.6 & $-5.4^{\star}$ & -1.7 & -4.0 \\
\hline Denmark & 2.1 & -1.8 & $9.5^{\star \star}$ & 194 & 4.4 & 4.0 & 4.3 \\
\hline Sweden & $-5.6^{\star \star}$ & $-7.3^{\star \star}$ & -0.2 & $-17^{\star \star}$ & -3.9 & $-3.5^{\star}$ & -4.5 \\
\hline \multicolumn{8}{|c|}{ AAGRs in the period 2007-2011 (\%) } \\
\hline All countries & $-3.9^{\star}$ & $-4.7^{*}$ & -1.5 & -2.4 & -1.1 & -2.0 & -6.4 \\
\hline Germany & -2.4 & -2.2 & $-3.3^{*}$ & -3.7 & -1.8 & -2.1 & -3.7 \\
\hline Italył & -5.6 & -4.4 & -7.6 & 14.4 & -5.4 & -7.6 & -6.4 \\
\hline Spain & 2.3 & -2.1 & $18.6^{*}$ & 5.5 & 3.0 & 1.0 & 0.7 \\
\hline France & $-6.0^{\star}$ & $-6.0^{\star}$ & $-6.0^{\star}$ & - & - & - & - \\
\hline The UK§ & $-6.3^{*}$ & $-6.5^{*}$ & -5.7 & -4.4 & \multicolumn{2}{|c|}{-3.8} & $-13^{\star}$ \\
\hline Belgium & -3.9 & -4.7 & 0.6 & -3.8 & -5.1 & -1.5 & -9.1 \\
\hline The Netherlands & -4.2 & -6.1 & -1.2 & -4.4 & -1.9 & -4.3 & -7.4 \\
\hline Austria & -2.0 & -1.9 & -2.4 & 9.4 & -0.5 & -1.2 & -9.8 \\
\hline Denmark & -1.8 & $-8.7^{\star}$ & $14.1^{*}$ & - & - & - & - \\
\hline Sweden & $-7.9^{\star}$ & $-11^{*}$ & 1.7 & $-13^{\star \star}$ & -4.3 & $-8.1^{*}$ & -6.4 \\
\hline \multicolumn{8}{|c|}{ AAGRs in the period 2012-2015 (\%) } \\
\hline All countries & 2.6 & 3.1 & 1.1 & -0.2 & -5.6 & -2.9 & 0.8 \\
\hline Germany & -0.2 & 0.0 & -1.3 & -3.4 & -2.2 & 2.5 & 7.6 \\
\hline Italy $\ddagger$ & -1.7 & -1.7 & -1.8 & 17.2 & -9.3 & -9.1 & -24 \\
\hline Spain & 2.3 & 4.4 & -4.3 & 3.9 & -1.8 & 5.1 & 0.4 \\
\hline France & 7.3 & 7.4 & 7.3 & - & - & - & - \\
\hline The UK§ & 3.9 & 4.5 & 1.7 & -1.4 & \multicolumn{2}{|c|}{$5.2^{*}$} & 5.0 \\
\hline Belgium & 5.0 & 4.3 & 7.7 & 2.7 & 0.2 & 7.3 & 14.2 \\
\hline The Netherlands & 2.3 & 6.7 & -3.7 & 4.6 & 16.2 & 0.5 & 4.8 \\
\hline Austria & -1.0 & 1.6 & -6.9 & 2.9 & -7.5 & 0.4 & -1.8 \\
\hline Denmark & 7.1 & 6.7 & 7.7 & 14.5 & 5.7 & 5.1 & 6.3 \\
\hline Sweden & 0.0 & -2.6 & $7.3^{*}$ & 12.0 & -6.2 & $-3.5^{\star}$ & 5.4 \\
\hline
\end{tabular}

+Data from Italy, France and Spain refer to the numbers of authorised clinical trials and not clinical trial applications.

†Phases can overlap. Thus, the summarised number of clinical trial applications for all trial phases is not necessarily equal to the total number of clinical trial applications registered.

$\ddagger A A G R$ in the period 2011-2015 for Italy only includes data from 2011 to 2014.

$\S$ In the UK, phase II and III clinical trials are registered together and could therefore not be separated.

ISome clinical trials are not specified by the sponsor in regards to the trial phase. The national competent authorities of Italy and the

Netherlands have registered these as not specified. These trials are not included in this table.

*Indicates $\mathrm{p}<0.05$.

**Indicates $\mathrm{p}<0.001$. 


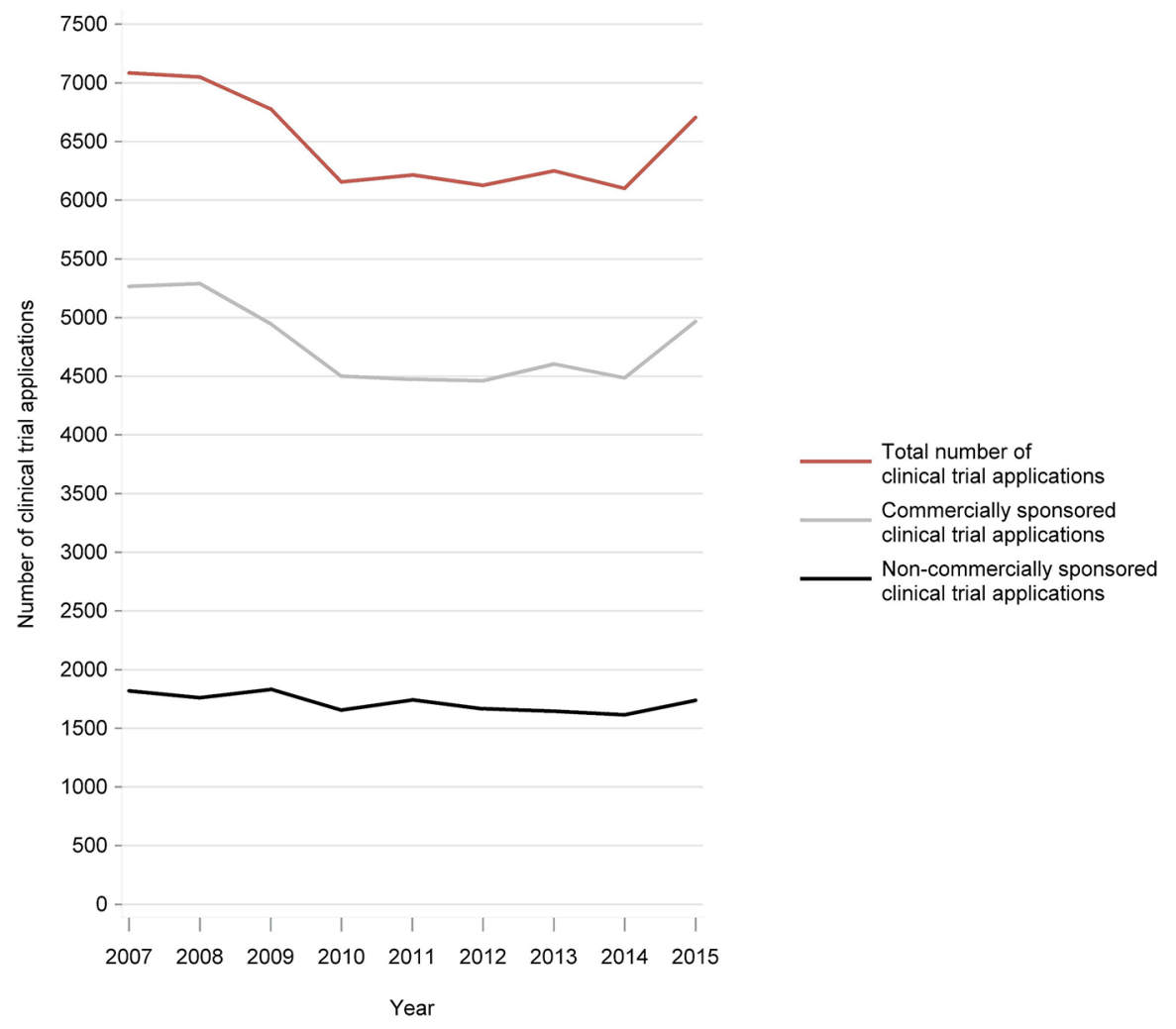

Figure 1 The summarised number of clinical trial applications in 10 Western European countries. The 10 included countries are Germany, Italy, Spain, France, the UK, Belgium, the Netherlands, Austria, Denmark and Sweden. The summarised number of clinical trial applications for 2015 is estimated as data from Italy regarding 2015 is not yet available from the national competent authorities. The number of clinical trials authorised in Italy in 2015 is therefore estimated.

(table 1). The percentage change was $12 \%$. As illustrated by figure $2 \mathrm{a}$ and table 1 , all countries except Spain experienced a decrease in the number of CTAs. Especially France, the UK and Sweden experienced a great decline with an AAGR of $-6.0 \%(\mathrm{p}=0.02),-6.3 \%(\mathrm{p}=0.01)$ and $-7.9 \%(\mathrm{p}=0.02)$, respectively.

The decrease in the summarised number of CTAs was primarily due to a decrease in commercially sponsored CTAs, which decreased significantly (AAGR $-4.7 \%$, $\mathrm{p}=0.01$ ), whereas the number of non-commercially sponsored CTAs decreased insignificantly (AAGR $-1.5 \%$, $\mathrm{p}=0.30$ ). All countries experienced a decrease in commercially sponsored CTAs, and six out of 10 a decrease in non-commercially sponsored CTAs. It is noteworthy that the modest summarised decrease in non-commercially sponsored CTAs was due to a considerable increase in non-commercially sponsored CTAs in Spain and Denmark (AAGR 18.6\% $(\mathrm{p}=0.01)$ and $14.1 \%(\mathrm{p}=0.04)$, respectively), whereas other countries such as Germany and France experienced a marked decline (AAGR $-3.3 \%$ $(\mathrm{p}=0.04)$ and $-6.0 \%(\mathrm{p}=0.03)$, respectively) (figure $2 \mathrm{c}$ and table 1). The summarised number of CTAs decreased within all trial phases, however not significantly. No other trends in the development of CTAs by type of trial phase were observed.

\section{The period 2012-2015}

From 2012 to 2015, the summarised number of CTAs did not change significantly (AAGR 2.6\% $(\mathrm{p}=0.27)$ ). The summarised number of CTAs was stable between 6101 and 6250 CTAs annually from 2012 to 2014, whereas it increased considerably from 2014 to 2015 (10\%). No countries experienced a significant change in the number of CTAs during the period (table 1). However, from 2014 to 2015, the number of CTAs increased in nine out of nine countries, and seven out of nine countries experienced an increase in both commercially sponsored and non-commercially sponsored CTAs (figures 2a, b and c).

No trends were observed in the development of CTAs by type of trial phase from 2012 to 2015 . There was an increase in the number of positive AAGRs regarding all trial phases in this period compared with the period 2007-2011.

\section{DISCUSSION}

This study showed that the development in the number of CTAs in Western Europe changed considerably during the period 2007-2015. From 2007 to 2011, nine out of 10 countries experienced a decrease in the number of CTAs, and the summarised number of CTAs decreased 


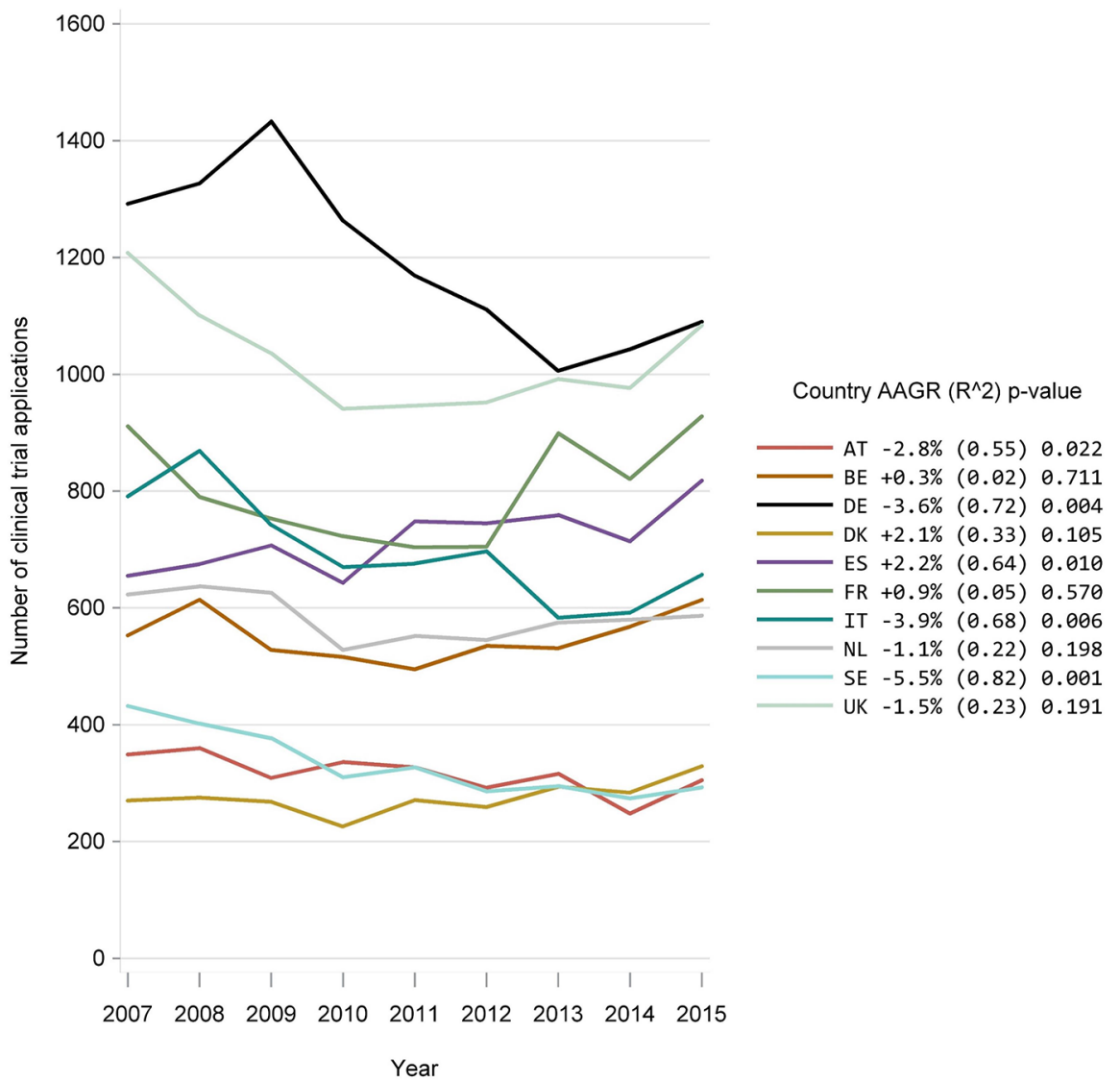

Figure 2a The total number of clinical trial applications in 10 Western European countries. AAGRs, average annual growth rates. Data from Italy, France and Spain refer to the numbers of authorised clinical trials and not clinical trial applications. The AAGRs, $R^{2} s$ and $p$ values are based on linear regression lines (not shown).

significantly with an AAGR of $-3.9 \%$. This decrease was followed by stagnation from 2012 to 2014 and subsequently a marked increase in the summarised number of CTAs of $10 \%$ from 2014 to 2015.

The negative development in the summarised number of CTAs from 2007 to 2011 was primarily due to a decrease in commercially sponsored CTAs (AAGR -4.7\%). In addition, it was due to a decrease within all trial phases. According to the European Commission, the number of CTAs supposedly decreased by $25 \%$ in the EU as a whole from 2007 to $2011 .^{2}$ In this study, the percentage change in the summarised number of CTAs was $12 \%$ during this period. Thus, one would expect a decrease in the number of CTAs in the Eastern European EU member states as well. Poland, the Czech Republic, Rumania and Hungary together with the countries included in this study account for the vast majority of clinical trials of medicines conducted in the EU. However, these four Eastern European EU member states did not experience a decrease in CTAs from 2007 to 2011 (refs 9-11, personal communication with the national competent authorities of Poland and Hungary). Consequently, our findings are more consistent with the 12\% decrease from 2007 to 2010 also reported by the European Commission. ${ }^{2}$

\section{Strengths and limitations of this study}

This is one of only few studies presenting detailed data on clinical trial activity in Western Europe. The study, therefore, adds information to the understanding of the clinical trial landscape in Europe. As the exact number of clinical trials of medicines and other clinical trials conducted (e.g. of medical devices and surgical procedures) is not publicly known, the development in the number of CTAs is one of the best indicators of clinical trial activity alongside data from clinical trial registries such as ClinicalTrials.gov, the WHO International Clinical Trials Registry Platform and the EU Clinical Trials Register. However, the data presented in this study do not precisely reflect the number of clinical trials of medicines conducted. First, some CTAs are rejected, and some trials are never conducted. Therefore, the number of CTAs in a country exceeds the actual number of trials. Second, multinational trials include CTAs in multiple countries. According to the European Commission, approximately $24 \%$ of all clinical trials of medicines applied for in the EU are multinational trials including CTAs in at least two member states. ${ }^{2}$ An increase in the summarised number of CTAs oneyear might be due to applications from a few large multinational trials and not an increase in the 


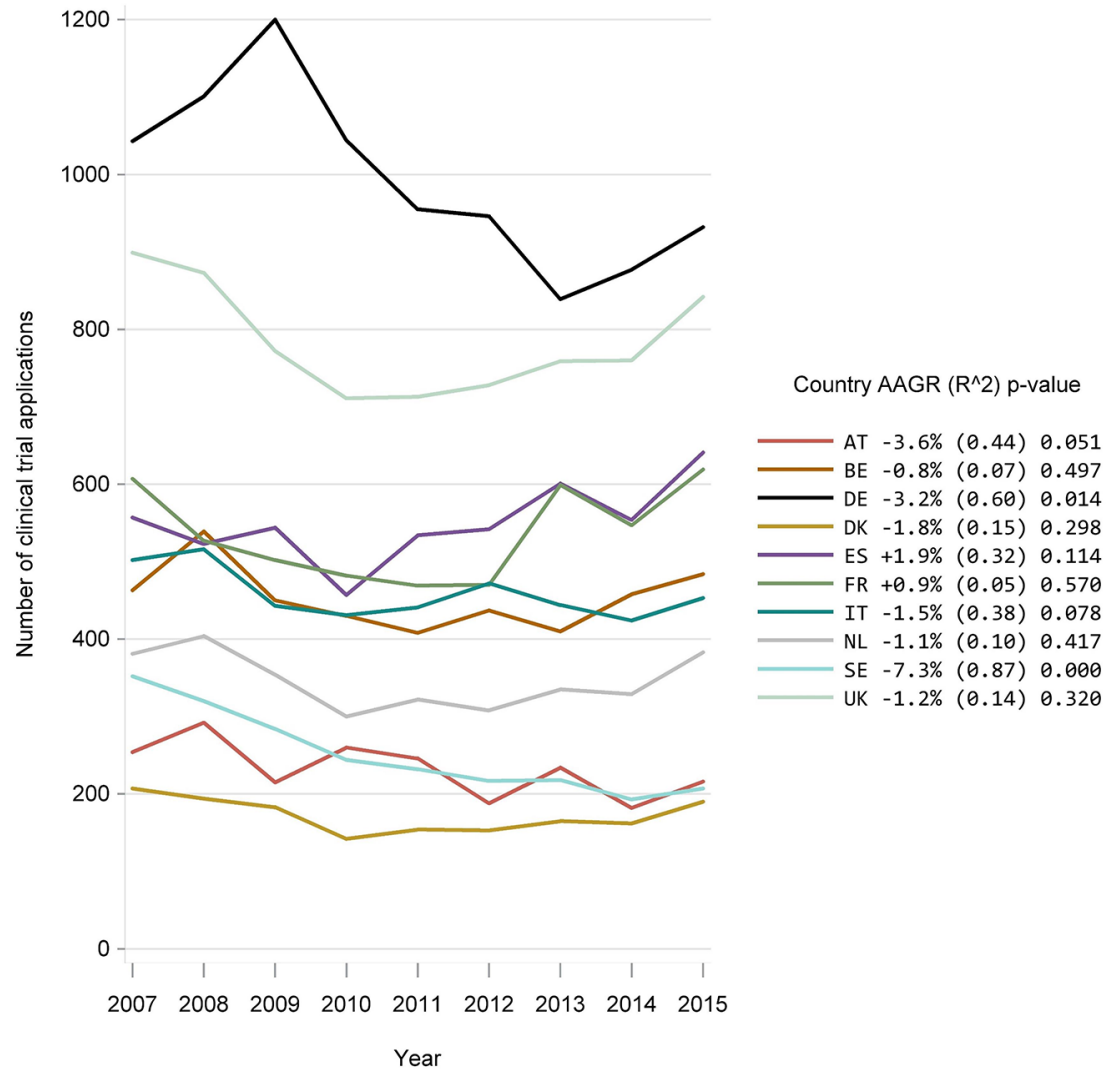

Figure $2 b$ The number of commercially sponsored clinical trial applications in 10 Western European countries. AAGRs, average annual growth rates. Data from Italy, France and Spain refer to the numbers of authorised clinical trials and not clinical trial applications. The national competent authorities of France states that approximately two-thirds of the clinical trials authorised annually in France are commercially sponsored, and one-third is non-commercially sponsored. The exact number of clinical trials by type of sponsor is unknown. The AAGRs, $R^{2} s$ and $p$ values are based on linear regression lines (not shown).

total number of clinical trials of medicines. Particularly commercially sponsored clinical trials are multinational, and therefore, the summarised number of CTAs for these trials reflects the true number of clinical trials of medicines less accurately compared with non-commercially sponsored CTAs. Still, the summarised number of CTAs is informative for the clinical trial activity; it makes a difference if a sponsor applies for conduction of a clinical trial in several European countries or only a few. Third, data regarding type of trial phase depend on information given by the sponsor in the application form. In these forms, more than one type of trial phase can be declared so that the application represents more than one type of phase.

In this study, six Western European EU member states were not included (Portugal, Ireland, Finland, Greece, Luxembourg and Malta). Moreover, Switzerland, Norway and Iceland were not included as these Western European countries are not EU member states. However, these nine countries together account for only approximately $10 \%$ of all CTAs in Western Europe. ${ }^{512-16}$ Therefore, we believe that the data presented are representative for Western Europe as a whole.
Data on type of trial phase were limited in this study. It was not possible to gain data from France on the distribution of CTAs by type of trial phase. Furthermore, it was not possible to evaluate the distribution of CTAs by type of sponsor with regard to trial phase as these data were not available from all countries and therefore not included. It should be noted that the summarised number of CTAs in 2015 is only an approximation as described in online supplementary appendix 2.

We used univariate linear regression analysis to evaluate the development in the number of CTAs over time. Therefore, we assumed that the development in the number of CTAs was linear over time which may not be the case. Furthermore, only few observations were present. Factors such as the financial crisis may explain some of the variation in the number of CTAs. However, such factors were not included in the current analysis due to few observations.

Possible explanations and comparison with other studies Many stakeholders have addressed that the European Clinical Trials Directive (EU 2001/20/EC) has had a negative effect on the conduction of clinical trials in 
400
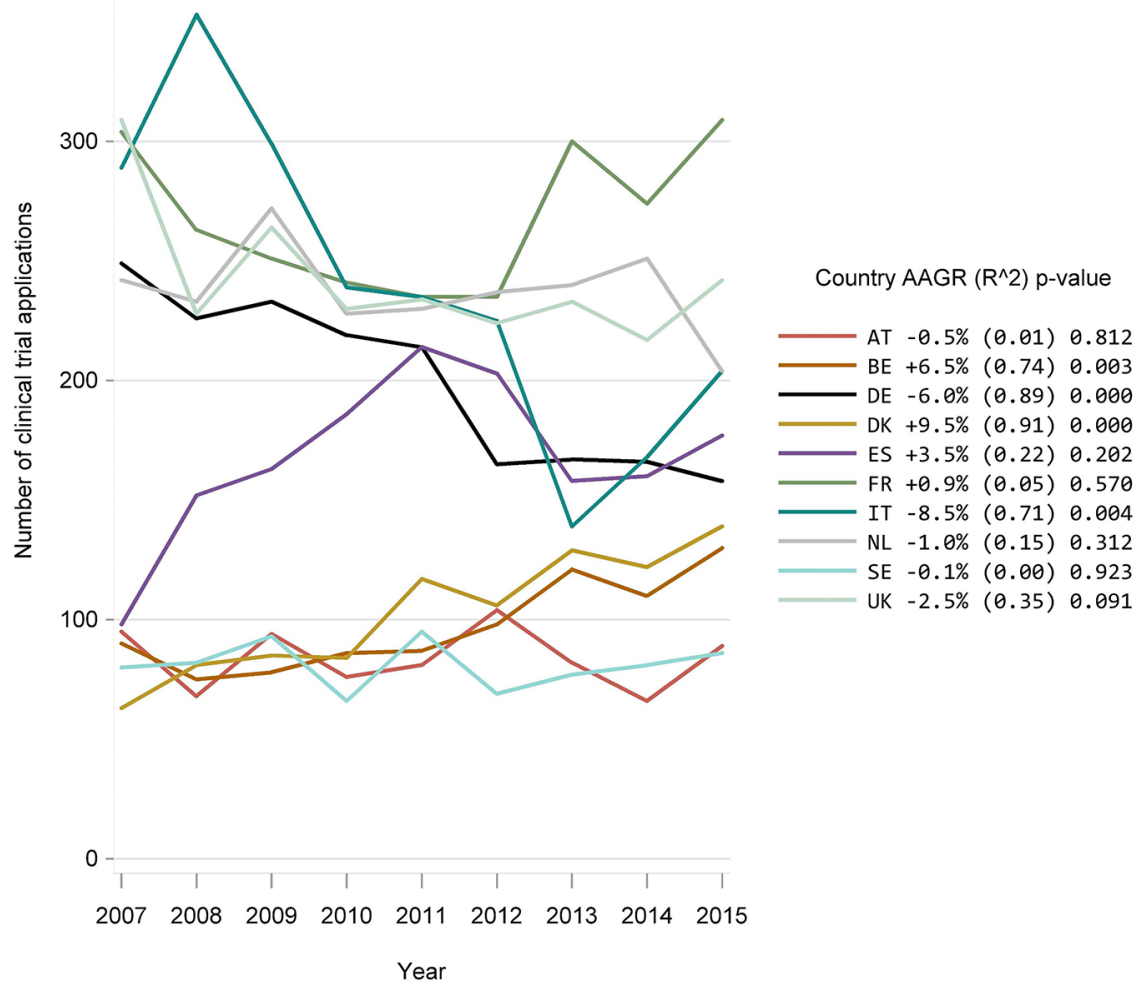

Figure 2c The number of non-commercially sponsored clinical trial applications in 10 Western European countries. AAGRs, average annual growth rates. Data from Italy, France and Spain refer to the numbers of authorised clinical trials and not clinical trial applications. The national competent authorities of France states that approximately two-thirds of the clinical trials authorised annually in France are commercially sponsored, and one-third is non-commercially sponsored. The exact number of clinical trials by type of sponsor is unknown. The AAGRs, $R^{2} s$ and $p$ values are based on linear regression lines (not shown).

Europe. Especially stakeholders involved in non-commercially sponsored trials have emphasised this. ${ }^{17-20}$ However, the cause for the observed decrease in CTAs is possibly multifactorial, and at least three other contributing factors should be considered: national and local political decisions, a potential global shift in clinical trial activity and the financial crisis initiated in 2007.

National and local political decisions influence the clinical trial landscape alongside EU regulations. For example, in contrast to other countries, Denmark had a stable increase in the number of non-commercially sponsored CTAs from 2007 to 2015, and the number was stable during the implementation of the directive. ${ }^{21}$ As pointed out by Berendt et al, the presence of publicly funded good clinical practice units presumably mitigated the negative effect of the directive as these units provide free assistance to academic researchers doing clinical research. Similar to Denmark, Italy took specific actions to support academic research following the implementation of the directive, and Italy experienced an increase in non-commercially sponsored CTAs every year from 2004 to $2008 .^{22}$ In 2009 though, a new decree demanded a higher level of insurance coverage for many academic institutions. ${ }^{4}$ This might explain the decrease in non-commercially sponsored CTAs in Italy from 2009 onwards. Thus, national and local political decisions can have a considerable impact on the clinical trial landscape, and it is likely that national initiatives, or the lack of such, have contributed to the decrease in CTAs from 2007 to 2011.

A global shift in clinical trial activity may also partly explain the decrease. Six recent studies analysed the global distribution of clinical trials using data from publicly available trial registries. ${ }^{23-28}$ Five of these six studies found that regions such as China, India and Japan hold an increasing share of the total number of clinical trials registered worldwide. The remaining study did not address this question but found that more than a quarter of clinical trials registered in ClinicalTrials.gov recruit participants in non-high-income countries. ${ }^{25}$ Other studies have also supported the hypothesis of a global shift. One study found that the number of active FDA-regulated investigators based outside the USA grew by $15 \%$ annually from 2002 to 2006, while the number of US-based FDA-regulated investigators declined. ${ }^{29}$ Regarding European trials, 


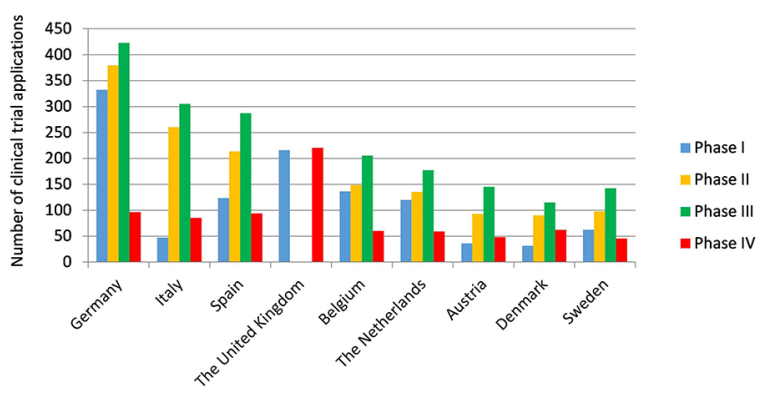

Figure 3 The average annually number of clinical trial applications by trial phase in nine Western European countries. The average annually number of clinical trial applications is based on data from 2007 to 2015. Phases can overlap. Thus, the summarised number of clinical trial applications for all trial phases is not necessarily equal to the total number of clinical trial applications registered. In the UK, phase II and III clinical trials are registered together and could therefore not be separated. The average number of clinical trial applications for phase II and III in the UK is 590. Data from Denmark regarding the number of clinical trial applications by trial phase are only from 2010 to 2015. Data from Italy and Spain refer to the numbers of authorised clinical trials and not clinical trial applications.

the number of patients recruited from Asian, Pacific and Middle Eastern countries in trials used for marketing authorisation applications to the European Medicines Agency increased substantially from 2005 to $2011 .{ }^{30}$ The financial crisis may have contributed to the decrease in CTAs in Europe and encouraged a shift to regions in which trial costs are lower. However, several crucial issues regarding a potential shift in clinical trial activity remain unclear. First, it is unclear whether the number of clinical trials is decreasing overall in traditional regions, or if other regions are just conducting more trials than before. Second, it is unclear whether the change in trial activity is primarily due to a shift in commercially sponsored trials or an increase in non-commercially sponsored trials. Third, it is possible that the increasing level of registration of clinical trials in trial registries leaves a biased impression of a global shift. Moreover, it is unclear if the potential global shift in clinical trial activity applies to clinical trials of medicines, as studies on global trial activity investigate clinical trials in general and not exclusively clinical trials of medicines.

After seven years of decrease and stagnation, the number of CTAs in Western Europe is now markedly increasing. This seems promising for the clinical trial landscape of Europe. However, it is yet unclear if this constitutes a transient fluctuation or a new trend. The increase in the number of CTAs in 2015 might simply result from a few large multinational trials. However, the positive development might continue due to the initiatives implemented to better the conditions for the conduct of clinical trials in Europe. Since the implementation of the Voluntary Harmonisation Procedure in 2009, the number of CTAs undergoing this procedure has increased considerably, and in 2015, 23\% of all multinational clinical trials of medicines underwent the procedure. ${ }^{31}$ This may have led to a faster regulatory time to approval and an increase in the number of multinational trials conducted in the EU. However, to our knowledge, this has not yet been investigated. A positive development in the number of CTAs may also be attributed to sponsors and administrative stakeholders becoming increasingly familiar with the new procedures that followed the EU directive. Moreover, the impact of the financial crisis on the pharmaceutical industry and national governments seems to be diminishing. However, it should be emphasised that the development in the clinical trial landscape is very complex with many global, national and local issues of influence.

\section{CONCLUSION}

This study found a significant decrease in the number of CTAs in Western Europe from 2007 to 2011 (AAGR $-3.9 \%)$. This development is possibly attributable to several factors such as the European Clinical Trials Directive, national and local political decisions, and a potential global shift in clinical trial activity. From 2014 to 2015, the number of CTAs increased markedly (10\%) after a period of stagnation from 2012 to 2014. Overall, there seems to be a positive development in the clinical trial landscape of Western Europe. However, it is yet too soon to determine if this constitutes a transient fluctuation or a new trend.

This study was limited to evaluating the development in the number of CTAs in Western Europe. Further research on the development in the number of CTAs in other geographic regions is required to compare the activity of clinical trials of medicines globally. Also, it is relevant to evaluate commercially and non-commercially sponsored CTAs by type of trial phase and distribution of national and multinational trials. Moreover, it would be interesting to investigate other aspects of clinical trials of medicines conducted, for example, which type of products are investigated, which therapeutic areas are represented and how many study participants are included.

Numerous issues influence the number of clinical trials of medicines conducted and several initiatives may be considered to attract and retain clinical trials. Among these, development of uniform regulatory processes, elimination of unnecessary bureaucratic procedures and development of standard contracts should be a priority. Furthermore, on a national level, optimisation of clinical trial units, evolvement of national disease-specific research networks and patient databases, availability of relevant information for the pharmaceutical industry on clinical trials and increased support for non-commercially sponsored clinical trials may be considered. However, knowledge of which factors influence the allocation of clinical trials is sparse, and a better understanding of this issue is important to improve the conditions for conduction of clinical trials and to attract and retain these 
regionally. Qualitative studies such as interviews among sponsors and clinical trial personnel would be suitable to illuminate this issue.

Acknowledgements We would like to thank Nicolai Jespersen for assisting with the statistical analysis, and we thank the following national competent authorities for providing data for this study on request: Bundesinstitut für Arzneimittel und Medizinprodukte, Germany; Paul-Ehrlich-Institut, Germany; The Federal Agency for Medicines and Health Products, Belgium; Centrale Commissie Mensgebonden Onderzoek, the Netherlands; Läkemedelsverket, Sweden; Urzad Rejestracji Produktów Leczniczych, Poland; and Országos Gyógyszerészeti és Élelmezésegészségügyi Intézet, Hungary.

Contributors TD, MH, UL and SFT designed the study. TD collected the data and developed the first draft of the manuscript. MH, UL and SFT contributed to the critical revision of the data and results and revised the manuscript. The final version of the manuscript is approved by all authors. TD is the guarantor.

Funding This study is funded by a research grant from The Capital Region of Denmark. The funder was not involved in the research, preparation or writing of this article, nor in the decision to submit it for publication.

Competing interests All authors have completed the ICMJE uniform disclosure form at www.icmje.org/coi_disclosure.pdf (available on request from the corresponding author) and declare: no support from any organisation for the submitted work other than those mentioned in the funding statement; $\mathrm{MH}$ reports research grants from private companies as stated in the disclosure form; these are not related to the submitted work; no other relationships or activities that could appear to have influenced the submitted work.

Provenance and peer review Not commissioned; externally peer reviewed.

Data sharing statement An overview of data sources is available as a supplemental file (appendix 1). Data are available from the corresponding author on request at dombernowsky@gmail.com.

Open Access This is an Open Access article distributed in accordance with the Creative Commons Attribution Non Commercial (CC BY-NC 4.0) license, which permits others to distribute, remix, adapt, build upon this work non-commercially, and license their derivative works on different terms, provided the original work is properly cited and the use is non-commercial. See: http://creativecommons.org/ licenses/by-nc/4.0/

(c) Article author(s) (or their employer(s) unless otherwise stated in the text of the article) 2017. All rights reserved. No commercial use is permitted unless otherwise expressly granted.

\section{REFERENCES}

1. European Medicines Agency. Clinical trials in human medicines [Internet]. 2016. http://www.ema.europa.eu/ema/index.jsp?curl= pages/special_topics/general/general_content_000489.jsp\&mid= WC0b01ac058060676f. (accessed 18 Aug 2016).

2. European Commission. Proposal for a Regulation of the European Parliament and of the Council on Clinical Trials on Medicinal Products for Human Use, and Repealing Directive 2001/20/EC. Brussels: European Commission, 2012.

3. Krafft H, Bélorgey C, Szalay G. Experience and further development with the voluntary harmonization procedure for multinational clinical trials in the European Union. Nat Rev Drug Discov 2012;11:419.

4. Hartmann M. Impact assessment of the European clinical trials directive: a longitudinal, prospective, observational study analyzing patterns and trends in clinical drug trial applications submitted since 2001 to regulatory agencies in six EU countries. Trials 2012;13:53.

5. Bengtström M, Nybond L. Clinical trials in the Nordic and Baltic countries: ScanBalt [Internet]. http://www.scanbalt.org/press/news\% 20archive/view?id=2894. (accessed 15 Dec 2015).

6. European Commission. Annex 1: Clinical Trial Application Form. Request for authorisation of a clinical trial on a medicinal product for human use to the competent authorities and for opinion of the ethics committees in the community. European Commission, 2009.

7. European Medicines Agency. B. Sponsor identification [Internet]. 2016. https://eudract.ema.europa.eu/help/content/eudract/section b_sponsor_id.htm. (accessed 20 Sep 2016).
8. European Medicines Agency. Note for guidance on general considerations for clinical trials (CPMP/ICH/291/95) [Internet]. 1998. http://www.ema.europa.eu/docs/en_GB/document_library/ Scientific_guideline/2009/09/WC500002877.pdf. (accessed 18 Aug 2016).

9. SÚKL. Annual report 2008 State Institute for Drug Control, Czech Republic [Internet]. 2008. http://www.sukl.eu/sukl/annual-reports. (accessed 18 Aug 2016).

10. Agentia Nationala a Medicamentului si a Dispozitivelor Medicale. 2012 Annual report The National Agency for Medicines and Medical devices [Internet]. 2012. http://www.anm.ro/anmdm/en/_/ACTIVITY\% 20REPORTS/Activity\%20report\%202012.pdf. (accessed 19 Aug 2016).

11. Agentia Nationala a Medicamentului si a Dispozitivelor Medicale. The National Medicines Agency 2007 annual report [Internet]. 2007. http://www.anm.ro/anmdm/en/_/ACTIVITY\%20REPORTS/2007\% 20Activity\%20report.pdf. (accessed 19 Aug 2016).

12. Swissmedic. Annual Report 2015 [Internet]. 2016. https://www. swissmedic.ch/suchen/index.html?qQ=annual+report\&lang=en\& search $=$. (accessed 19 April 2017).

13. Infarmed. Statistics of Clinical Trials Assessed by Infarmed: Infarmed. 2016. http://www.infarmed.pt/web/infarmed-en/human-medicines/ statistics-of-clinical-trials-assessed-by-infarmed. (accessed 19 April 2017).

14. Icelandic Medicines Agency. Key figures from the annual report 2011 [Internet]. 2011. https://www.ima.is/publications/statistics/key_ figures/. (accessed 19 April 2017).

15. HPRA. Annual Report 2015 [Internet]. 2016. https://www.hpra. ie/docs/default-source/publications-forms/corporate-policydocuments/hpra-annual-report-2015.pdf?sfvrsn=11. (accessed 19 April 2017)

16. EU Clinical Trial Register. European Medicines Agency [Internet]. 2017. https://www.clinicaltrialsregister.eu/ctr-search/search.

17. Frewer LJ, Coles D, Champion K, et al. Has the European Clinical Trials Directive been a success? BMJ 2010;340:c1862.

18. Hearn J, Sullivan R. The impact of the 'Clinical trials' Directive on the cost and conduct of non-commercial cancer trials in the UK. Eur $J$ Cancer 2007;43:8-13.

19. Keim B. Tied up in red tape, European trials shut down. Nat Med 2007;13:110.

20. Singer EA, Druml C. Collateral damage or apocalypse now for european academic research. Intensive Care Med 2005;31:271.

21. Berendt L, Hakansson C, Bach KF, et al. Effect of European clinical trials directive on academic drug trials in Denmark: retrospective study of applications to the Danish Medicines Agency 1993-2006. BMJ 2008;336:33-5.

22. Agenzia Italiana del Farmaco. Clinical trials of drugs in Italy 2010 [Internet]. 2010. http://www.agenziafarmaco.gov.it/en/content/ bulletin-clinical-trials-drugs-italy. (accessed 9 Dec 2015).

23. Atal I, Trinquart L, Porcher R, et al. Differential globalization of industry- and Non-Industry-Sponsored clinical trials. PLOS One 2015; 10:e0145122.

24. Drain PK, Robine M, Holmes KK, et al. Trail watch: global migration of clinical trials. Nat Rev Drug Discov 2014;13:166-7.

25. Murthy S, Mandl KD, Bourgeois FT. Industry-sponsored clinical research outside high-income countries: an empirical analysis of registered clinical trials from 2006 to 2013. Health Res Policy Syst 2015;13:28.

26. Novak T, Belotserkovsky M, Payeur G. Decline of Clinical Trials in Central and EasternEurope: Fluctuation or Trend? Appl Clin Trials [Internet]. 2014. http://www.appliedclinicaltrialsonline.com/declineclinical-trials-central-and-eastern-europe-fluctuation-or-trend. (accessed 18 Aug 2016).

27. Thiers FA, Sinskey AJ, Berndt ER. Trends in the globalization of clinical trials. Nat Rev Drug Discov 2008;7:13-14.

28. Viergever RF, Li K. Trends in global clinical trial registration: an analysis of numbers of registered clinical trials in different parts of the world from 2004 to 2013. BMJ open 2015;5:e008932.

29. Getz K. Global clinical trials activity in the details. Appl Clin Trials [Internet]. 2007. http://www.appliedclinicaltrialsonline.com/globalclinical-trials-activity-details. (accessed 20 May 2016).

30. European Medicines Agency. Clinical trials submitted in marketingauthorisation applications to the European Medicines Agency. London: European Medicines Agency. (accessed 11 Dec 2013).

31. Heads of Medicines Agencies. Results of the Voluntary Harmonisation Procedure 2009 -2016 [Internet]. http://www.hma.eu/ 392.html. (accessed 19 April 2017). 